Original Research

\title{
Implementation of pharmacist-led services in primary \\ care: A mixed-methods exploration of pharmacists' perceptions of a national educational resource package
}

\author{
Kate PRESTON (D), Natalie M. WEIR (D), Tanja MUELLER ${ }^{(D)}$, Rosemary NEWHAM ${ }^{(D)}$, Marion BENNIE(D). \\ Received (first version): 26-May-2021 \\ Published online: 13-Sep-2021
}

\begin{abstract}
Background: To help alleviate the global pressure on primary care, there has been an increase in the number of clinical pharmacists within primary care. Educational resources are necessary to support this workforce and their development within this role. An educational resource package was developed in Scotland to support the General Practice Clinical Pharmacists (GPCPs), containing a hard copy Competency and Capability Framework (CCF), an online platform (TURAS) and both clinical and educational supervisors in 2016.

Objective: To examine the implementation of a competency-based educational resource package through the exploration of pharmacists' perceptions of its adoption, acceptability, appropriateness, and feasibility.

Methods: Participants were GPCPs who had been part of a national training event between 2016 and 2018. The participants were given the opportunity to complete an online questionnaire or a semi-structured telephone interview. Both data collection tools were based on Proctor's model of implementation outcomes: adoption, acceptability, appropriateness and feasibility. Areas covered included GPCPs' perceptions and level of adoption of the educational resource package developed to support them in their role.

Results: Of a potential 164 participants, $52(31.7 \%)$ completed the questionnaire and $12(7.3 \%)$ completed the interview. GPCPs indicated widespread adoption and were accepting of the resources; however, it was suggested that its value was undermined, as it was not associated with a qualification. The appropriateness and feasibility of the resources depended on GPCPs' individual situation (including current role, previous job experience, time available, support received from peers and supervisors, and perceptions of resources available).

Conclusions: The suitability of the CCF was evidenced by participants' adoption and acceptance of the resource, indicating the necessity of a competence-based framework to support the GPCPs' role. However, its suitability was hindered in terms of varied perceptions of appropriateness and feasibility. Despite the limited sample size, the results indicate that the value of these resources should be promoted across primary care; nevertheless further facilitation is required to allow GPCPs to fully engage with the resources.
\end{abstract}

Keywords

Pharmacists; General Practice; Primary Health Care; Pharmaceutical Services; Delivery of Health Care; Regional Health Planning; Perception; Program Evaluation; Surveys and Questionnaires; Qualitative Research; Scotland

\section{INTRODUCTION}

There are increasing challenges within primary care due to aging populations and the rise of multi-morbidity. ${ }^{1-4}$ Primary care across several countries have experienced low levels of staff satisfaction and difficulties with General Practitioner (GP) recruitment and retention. ${ }^{5-8}$ In the United Kingdom (UK), there is widespread GP dissatisfaction. ${ }^{9}$ A report in 2019 found that, within two years, GPs' morale had reduced by $59.4 \%$, and $48.5 \%$ of GPs were preparing to leave practice. ${ }^{9}$ The GPs believed that greater public knowledge and increased funding and support staff would help to improve their working

Kate PRESTON. BA (Hons), MSc. Strathclyde Institute of Pharmacy and Biomedical Science, University of Strathclyde. Glasgow (United Kingdom).kate.preston@strath.ac.uk

Natalie M. WEIR. MPharm, PhD. Strathclyde Institute of Pharmacy and Biomedical Science, University of Strathclyde. Glasgow (United Kingdom).natalie.m.weir@strath.ac.uk

Tanja MUELLER. MPharm (equiv), MPH, PhD. Strathclyde Institute of Pharmacy and Biomedical Science, University of Strathclyde. Glasgow (United Kingdom). tanja.muller@strath.ac.uk

Rosemary NEWHAM. BA (Hons), MRes, PhD. Strathclyde Institute of Pharmacy and Biomedical Science, University of Strathclyde. Glasgow (United Kingdom). rosemary.e.newham@strath.ac.uk Marion BENNIE. BSc, MSc (Clin Pharm). Strathclyde Institute of Pharmacy and Biomedical Science, University of Strathclyde. Glasgow (United Kingdom). marion.bennie@strath.ac.uk environment. ${ }^{9}$

To alleviate pressure, and improve patient safety and care, clinical pharmacists have been introduced in primary care. ${ }^{1}$ Research has suggested that these pharmacists save GPs' time, increase morale, and reduce stress. ${ }^{3}$ Furthermore, some patients show improved understanding of their medication after a consultation with a primary care pharmacist. ${ }^{10}$ However, challenges are apparent. One study suggested that patients felt they would benefit from further guidance on pharmacists' capabilities and services. ${ }^{11}$ Other challenges include that pharmacists may take longer than GPs to complete tasks, GPs' limited knowledge of the pharmacists' role, and patients preferring to see a GP. ${ }^{12-14}$ To alleviate these challenges, research suggests there should be an agreement over the role of pharmacists within primary care, with a defined job role and clarity of what tasks pharmacists should complete. ${ }^{2}$

In Scotland, funding was made available in 2015 to increase the number of pharmacists working within primary care (termed General Practice Clinical Pharmacists (GPCPs)). Their roles were defined by GPs or local priorities, resulting in GPCPs undertaking a wide variety of tasks. ${ }^{4}$ GPCPs could work in several different practices, which hindered continuity and integration. ${ }^{4}$ To increase consistency in the 
GPCPs' role, the 'pharmacotherapy service' was developed in $2018{ }^{15}$ This service stratified GPCPs' tasks into core (Level 1), advanced (Level 2) and specialist (Level 3). The types of tasks depend on the area and the availability of the workforce, but it is expected that pharmacists would become integral within the primary care team. ${ }^{15}$

As pharmacy services within primary care develop and responsibilities increase, it is vital that this is underpinned by effective educational resources that support clinical pharmacists' development. Within healthcare the use of competency-based educational resources to support a workforce is common, evidence based, and has prepared professionals for patient facing roles within nursing, pharmacy and psychology. ${ }^{16-19}$ A competency is defined as knowledge, skills, behaviours and attitudes that influence an individual's role, and can be improved through training and development. ${ }^{20}$ A systematic review found that competency based frameworks improved pharmacists' performance, by allowing them to evaluate their work and recognise learning gaps. ${ }^{21}$ Further to this, evaluations of post-graduate training for community pharmacists within the UK have found that the use of work-based training is appropriate and necessary to support pharmacists in the development of their competence and confidence. ${ }^{22,23}$ Countries including Australia, Canada, the Netherlands and the UK have developed competency-based educational resources which outline the tasks that clinical pharmacists should complete in primary care. ${ }^{17,24-27}$ While these resources have shown to be effective in improving confidence, patient communication, and teamwork, there is little research showing the suitability of competencybased training programs in supporting pharmacists working in the primary care setting. ${ }^{26,28}$

In Scotland, a competency based educational resource package was created in 2016 by NHS Education for Scotland (NES) to support GPCPs' development. The package comprises a hard-copy of the "Competency and Capability Framework" (CCF) and an online resource named TURAS. ${ }^{29}$ Clinical and educational supervision is also provided, which has been highlighted as beneficial for competency-based education. $^{29-31}$ Clinical supervisors provide GPCPs with guidance within their practice, while educational supervisors take on a supportive role offering constructive feedback on competence, capabilities and the completion of the CCF. ${ }^{29}$ The CCF is stratified into three levels (Advanced 1, Advanced 2 and Mastery) which contain competencies and capabilities that GPCPs should develop. The three levels of the CCF do not directly map on to the levels of the pharmacotherapy service. Documentation of the tasks undertaken as part of the pharmacotherapy service, alongside other work-related activities, provide evidence regarding the GPCPs' competencies when completing the CCF. TURAS is available for participants to submit documented evidence, with access to an online copy of the CCF and further e-learning.

While previously implemented work and competencybased education has been shown to be necessary and appropriate in other pharmacy settings, there is limited research looking at its use in primary care. ${ }^{28}$ To understand the use of competency-based education in this setting, it is important to gauge how it's implementation will impact important outcomes. Proctor's model of implementation outcomes sets out the areas of interest when introducing a new innovation, which include adoption, acceptability, appropriateness, feasibility, fidelity, cost, penetration, and sustainability. ${ }^{32}$ The model suggests that the successful implementation of an innovation is necessary for it to effectively support development and has been shown to be beneficial in several areas, including the integration of pharmacy services. ${ }^{32,33}$ Therefore, the aim of this study is to gauge perceptions of the competency-based educational resource package created for GPCP in Scotland through the use of Proctor's implementation outcomes. This will allow increased understanding of the features underpinning effective implementation of competency-based education.

\section{METHODS}

\section{Design}

A mixed-method approach was taken, utilising an online questionnaire and semi-structured telephone interviews. The two methods were completed concurrently, with the results integrated at the reporting stage to gain an in-depth understanding of GPCPs' perceptions of the CCF and its supporting resources. ${ }^{34}$ Proctor's model of implementation outcomes was used as a theoretical framework to inform the development of the research material described below. $^{32}$ This study focused on early implementation outcomes as the educational resource package was introduced recently (2016). The outcomes of interest and their descriptions are presented in Table $1 .^{32}$

\section{Development of materials}

Two tools were developed: a questionnaire and a semistructured interview schedule. Both tools collected the same demographics, e.g. gender, years' experience working in General Practice, use of the individual resources within the competency-based educational resource package, and pharmacotherapy service tasks they complete.

\section{Questionnaire}

A reliable and validated questionnaire developed by Weiner was used. ${ }^{35}$ This questionnaire was based on Proctor's model of implementation outcomes and was used

\begin{tabular}{|l|l|}
\hline \multicolumn{2}{|l|}{ Table 1. Proctor's model outcomes of interest } \\
\hline Proctor's outcomes & \\
\hline Adoption & $\begin{array}{l}\text { The intention, initial decision, or action to try or employ an innovation or evidenced-based practice. Adoption } \\
\text { also may be referred to as "uptake" }\end{array}$ \\
\hline Acceptability & $\begin{array}{l}\text { The perceptions among implementation stakeholders that a given treatment, service, practice, or innovation is } \\
\text { agreeable, palatable, or satisfactory }\end{array}$ \\
\hline Appropriateness & $\begin{array}{l}\text { The perceived fit, relevance, or compatibility of the innovation of evidence-based practice for a given practice } \\
\text { setting, provider, or consumer; and/or perceived fit of the innovation to address an issue or problem. }\end{array}$ \\
\hline Feasibility & $\begin{array}{l}\text { The extent to which a new treatment, or an innovation, can be successfully used or carried out within a given } \\
\text { agency or setting }\end{array}$ \\
\hline
\end{tabular}


to explore GPCPs' views on the acceptability, appropriateness, and feasibility of the CCF. ${ }^{32}$ Each area was examined through four items rated on a five-point Likert scale $(1=$ completely disagree, $2=$ disagree, $3=$ neither agree nor disagree, $4=a g r e e, 5=$ completely agree), with openended questions to elicit further comments.

The questionnaire was anonymous and delivered on the online platform Qualtrics (Qualtrics. Provo UT, USA). It was piloted by six pharmacists, of which five had experience working within the general practice setting, to ensure relevance and clarity. Piloting resulted in minor rewording, which was not considered to impact on the reliability and validity of the questionnaire. The reworded questionnaire was piloted by three GPCPs with no further suggested changes.

\section{Semi-structured interview}

The semi-structured interview schedule was developed based on Proctor's model. ${ }^{32}$ The interview schedule explored:

\section{Description of the CCF's features}

2. Experience with the CCF, the online portfolio TURAS, Clinical and Educational supervision

3. Adoption of the CCF

4. Acceptability of the CCF

5. Appropriateness of the CCF

6. Feasibility of the CCF

The interview schedule was piloted by three GPCPs which resulted in minor changes relating to wording.

\section{Recruitment}

Participants were GPCPs who had participated in a national training event for GPCPs offered between 2016 and 2018. NHS Education for Scotland (NES) emailed eligible participants a Participant Information Sheet and asked them to respond if they did not want to be contacted by the university. The email addresses of those who did not opt-out were provided to the research team. The participants were emailed the link to the questionnaire and invited to participate in the telephone interview. Email reminders were periodically sent out to maximise the response rate. For the interview participants, data collection was initially done by convenience sampling, with all potential participants contacted; however, once saturation was reached potential interviewees were purposefully sampled to balance the demographics. The interview and questionnaire data collection occurred between July and October 2019.

\section{Analysis}

Potential participants were given the opportunity to complete both the interview and questionnaire, which may have resulted in participants taking part in both. Therefore, the questionnaire and interview results were analysed separately. Medians, frequencies and percentages were calculated for the demographic data for both the interview and questionnaire responses.

\section{Questionnaire}

Questionnaire responses comprised both qualitative (freetext responses) and quantitative data. For the quantitative data Cronbach's alpha test statistic was used to assess if the section was reliable (alpha $\geq 0.09$ excellent; $0.09>$ alpha $\geq 0.08$ good; $0.8>$ alpha $\geq 0.07$ acceptable; $0.07>$ alpha $\geq$ $0.6=$ =questionable; 0.6 >alpha $\geq 0.5=$ poor; $0.5>$ alpha unacceptable). ${ }^{36}$ The median and interquartile range (IQR) were calculated for the acceptability, appropriateness and feasibility questionnaire sections. For adoption of individual resources, percentages were calculated. The qualitative data from the open-ended questions underwent a content analysis which aims to both describe and quantify data by grouping it under different categories, which can be created prior to or during the analysis. ${ }^{37}$ For the current study, the data from the free text responses were grouped under each of the implementation outcomes categories, with $10 \%$ of the analysis independently validated.

Interview

The data from the interviews underwent intelligent verbatim transcription, and the framework approach was used to structure the data. ${ }^{38}$ This first involved developing a coding matrix covering adoption, acceptability, appropriateness, and feasibility. This was then applied to all transcripts, with $10 \%$ independently validated. Disagreement was resolved through discussion and consensus. The acceptability, appropriateness and feasibility data from the interviews underwent thematic analysis, to understand the connections and patterns across the data. ${ }^{39}$ The remaining data underwent a summative content analysis, with the aim to quantify the data under different categories, with the results presented as frequencies and percentages. ${ }^{37}$ Adoption data were taken from the demographic section, where participants were asked which resources they used.

\section{Ethical approval}

The Strathclyde Institute of Pharmacy and Biomedical Science ethics committee approved the study (18/19 EA08, May 2019) and, as this is a service evaluation, it was exempt from NHS ethical and management review.

\section{RESULTS}

Interview and questionnaire data are presented together for a fuller understanding of the educational resource package; however, a sub-set of the questionnaire participants may have also completed the interview therefore the demographics are presented separately. For the questionnaire, Cronbach's Alpha test statistics indicated a good-excellent level of reliability (alpha $=0.83$ 0.94). ${ }^{37}$

Due to the recruitment methods, the data is based on the 164 pharmacists who stated that they would like to be contacted by the research team as the total population of GPCPs is unknown. Of the 164 potential participants, 52 $(31.7 \%)$ completed the questionnaire and 12 (7.3\%) completed the semi-structured telephone interviews (Table 2). The majority of the questionnaire and interview participants were female $(59.6 \%, 83.3 \%$ respectively) and aged between $25-44$ years (59.6\%, 91.6\% respectively). 


\begin{tabular}{|c|c|c|}
\hline Characteristics & $\begin{array}{c}\text { Interviews ( } \mathrm{n=12)} \\
\mathrm{N}(\%) \\
\end{array}$ & 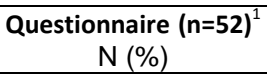 \\
\hline \multicolumn{3}{|l|}{ Gender } \\
\hline Male & $2(16.7 \%)$ & $11(21.2 \%)$ \\
\hline Female & $10(83.3 \%)$ & $31(59.6 \%)$ \\
\hline Prefer not to say & $0(0 \%)$ & $1(1.9 \%)$ \\
\hline Did not complete & $0(0 \%)$ & $9(17.3 \%)$ \\
\hline \multicolumn{3}{|l|}{ Years' experience; median (IQR) } \\
\hline qualified as a pharmacist & $11(6-18.5)$ & $15(10-20)$ \\
\hline working in a GP practice & $3.25(3-3.6)$ & $3(3-3)$ \\
\hline \multicolumn{3}{|l|}{ NHS Health Regions ${ }^{2}$} \\
\hline Ayrshire and Arran & $0(0 \%)$ & $2(3.8 \%)$ \\
\hline Borders & $0(0 \%)$ & $1(1.9 \%)$ \\
\hline Dumfries and Galloway & $0(0 \%)$ & $2(3.8 \%)$ \\
\hline Fife & $1(8.3 \%)$ & $3(5.8 \%)$ \\
\hline Forth Valley & $0(0 \%)$ & $5(9.6 \%)$ \\
\hline Grampian & $2(16.7 \%)$ & $3(5.8 \%)$ \\
\hline Greater Glasgow and Clyde & $3(25 \%)$ & $9(17.3 \%)$ \\
\hline Lanarkshire & $1(8.3 \%)$ & $9(17.3 \%)$ \\
\hline Highlands & $1(8.3 \%)$ & $2(3.8 \%)$ \\
\hline Lothian & $2(16.7 \%)$ & $3(5.8 \%)$ \\
\hline Orkney & $0(0 \%)$ & $1(1.9 \%)$ \\
\hline Shetland & $1(8.3 \%)$ & $2(3.8 \%)$ \\
\hline Tayside & $1(8.3 \%)$ & $5(9.6 \%)$ \\
\hline Western Isles & $0(0 \%)$ & $1(1.9 \%)$ \\
\hline Did not complete & $0(0 \%)$ & $9(17.3 \%)$ \\
\hline \multicolumn{3}{|l|}{ Have you experienced any clinical supervision? } \\
\hline 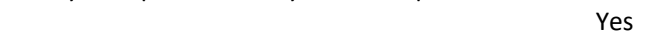 & $9(75.0 \%)$ & 27 (51.9\%) \\
\hline No & $3(25.0 \%)$ & $15(28.8 \%)$ \\
\hline I don't know & $0(0 \%)$ & $1(1.9 \%)$ \\
\hline Did not complete & $0(0 \%)$ & $9(17.3 \%)$ \\
\hline \multicolumn{3}{|l|}{ Have you experienced any educational supervision? } \\
\hline Yes & $9(75.0 \%)$ & $29(55.8 \%)$ \\
\hline No & $3(25.0 \%)$ & $14(26.9 \%)$ \\
\hline I don't know & $0(0 \%)$ & $0(0 \%)$ \\
\hline Did not complete & $0(0 \%)$ & $9(17.3 \%)$ \\
\hline
\end{tabular}

There was representation from all 14 NHS Health regions within Scotland in the questionnaire data and a median of 3 (IQR= 3.0-3.0) years' experience in General Practice. Interview participants represented 8 Health regions and had 3.25 (IQR= 3.0-3.6) median years' experience in General Practice.

The percentage of participants who stated they had undertaken tasks that were part of the pharmacotherapy service is presented in Table 3. Tasks could be completed face-to-face, over the phone, or by referring to patient's notes. The results suggest that the most common tasks completed by the interview participants were authorising/actioning immediate discharge letters, medicines reconciliation, and medication review (5+ medicines). For the questionnaire participants the most common task completed was formulary adherence. The results also indicated that the task undertaken the least was specialist clinics in both the interview and questionnaire groups.

Adoption refers to the participants' use of the supporting resources provided. The findings indicated that most participants used both the hard copy of the CCF and TURAS, as presented in Table 4, and a minority did not use either resource. The results also suggest that often a participant would use both resources, rather than just one.
Acceptability refers to participants' perceptions on whether the hard copy of the CCF was a satisfactory resource for educating GPCPs. The questionnaire's median response was 3.5 (IQR= 2.9-4.0) which indicates a slightly positive view on the acceptability of the CCF. Two main themes emerged from the interview and free-text questionnaire data pertaining to acceptability: (1) perceived purpose and (2) worth of the CCF.

The perceived purpose of the CCF influenced GPCPs' perceptions of its acceptability, with some participants using the CCF to evidence their current level of competence as a GPCP:

"As far as I'm aware the purpose is to just to prove we are competent for the role..." (P10)

Other participants reported using it as a tool to identify personal development opportunities in order to further their growth within the role:

"It gets you to identify areas that you're maybe lacking in, or areas that you would need to focus on..." (P3)

The acceptability of the CCF was also related to the whether GPCPs believed it to be a worthwhile activity both to themselves and the wider team within the General Practice. Participants had mixed views on the worth of the CCF, with some finding it helped aid reflection by allowing 


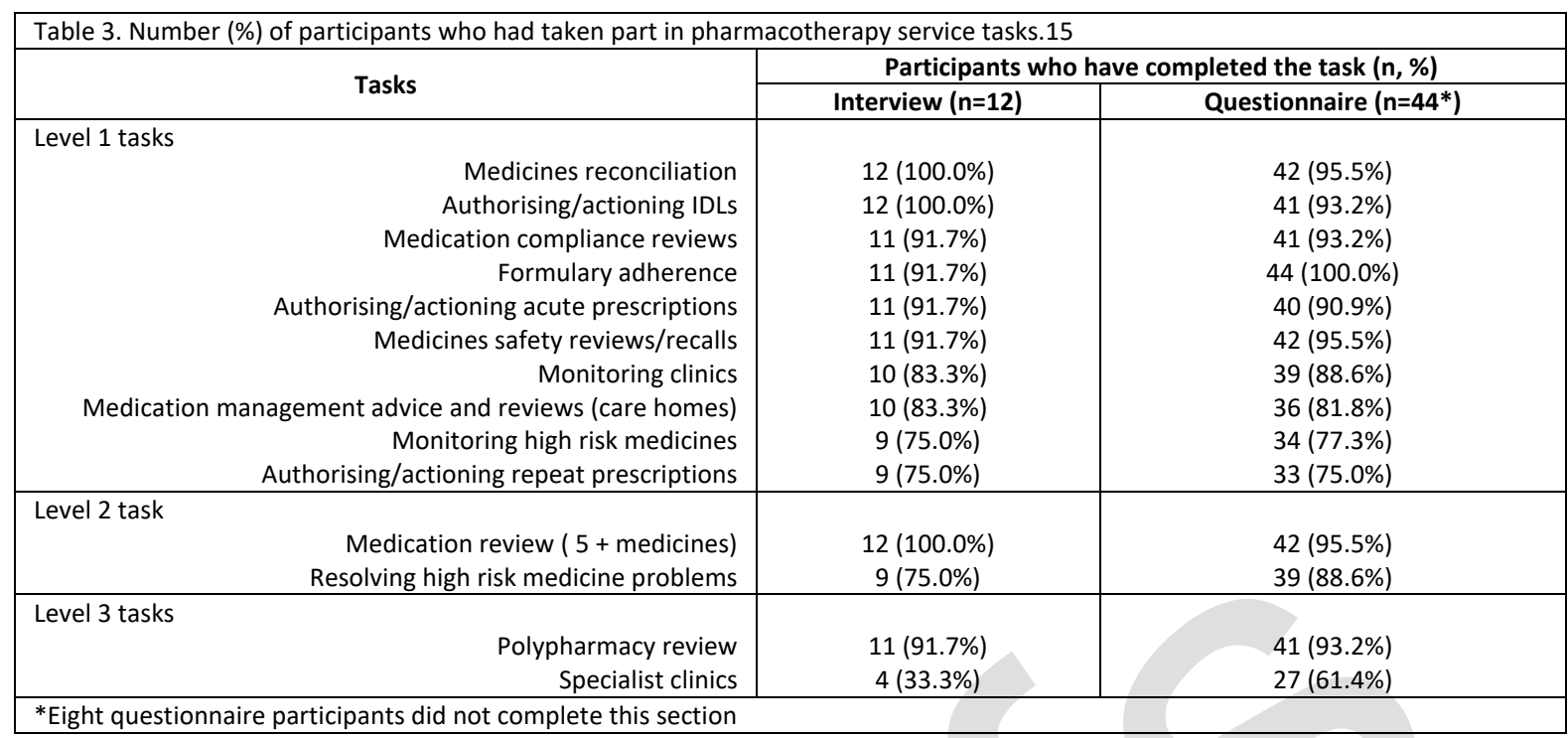

GPCPs to realise competencies they had overlooked. Others felt that it helped standardise the role of a GPCP, by reducing variation and providing guidance on the tasks they should complete. However, some suggested that because completing the CCF did not result in a qualification, it would not be recognised and therefore its full worth would not be realised:

“...we need to...find its place in getting it to be a recognised qualification. That's my big concern with it that if it's never recognised and fully acknowledged I suspect" (P2)

The appropriateness of the CCF refers to whether participants believe its completion was appropriate based on their current and previous job roles. The questionnaire found a median response of $4.0(\mathrm{IQR}=3-4)$ which suggests a positive view on the appropriateness. Two main themes emerged from the interview and free-text questionnaire data: (1) job role opportunities and (2) previous experience.

The opportunities participants had within their role was linked to the appropriateness of the CCF. Participants felt that those who had more patient facing opportunities would find the CCF easier and more appropriate to complete than those who did not. This was a result of them taking part in certain tasks that would allow them to complete sections of the CCF, such as physical examination:

"I guess some people who aren't seeing patients will struggle to meet some of it but if you're seeing patients then you're going to meet all the physical examination side" (P14)

Previous working experience of the participants also influenced how appropriate the CCF was to them as a
GPCP. It was suggested that previous experience in a hospital setting would result in greater clinical confidence, whereas those from a community pharmacy background may be better at dealing with drug related queries. However, having worked in General Practice prior to the CCF's introduction was suggested to negatively influence its appropriateness:

"...this framework appears to be aimed at pharmacists just starting in General Practice and is hard for experienced pharmacists established in General Practice to complete" (P26)

Feasibility relates to the extent with which the educational resource package can be easily completed by GPCPs. A median response of $3(I Q R=3.0-4.0)$ from the questionnaire indicates that participants were neutral about the feasibility of the CCF's hard copy. Three themes were identified in relation to feasibility: (1) time; (2) support; and (3) resource format and content.

Time negatively influenced the feasibility of the CCF. Participants suggested they did not have enough time during their working day which resulted in them having to complete the CCF out-with working hours. It was indicated that GPCPs were meant to have a half day a month to complete the framework, but their workload did not enable this to happen:

"You should get a half day every month if you're full time to submit it... I'm actually doing it in my own time because I don't have time during the week to do it, it's quite hard." (P5)

The support the GPCPs received influenced the feasibility of the CCF, with some participants feeling that they did not

\begin{tabular}{|c|c|c|}
\hline \multirow{2}{*}{ Resource } & \multicolumn{2}{|c|}{ Participants' use of resources; $n$ (\%) } \\
\hline & Questionnaire $(n=43)$ & Interview $(\mathrm{n}=12)$ \\
\hline TURAS + CCF's hard copy & $34(79.1 \%)$ & $9(75 \%)$ \\
\hline TURAS only & $5(11.6 \%)$ & $0(0.0 \%)$ \\
\hline CCF's hard copy only & $1(2.3 \%)$ & $1(8.3 \%)$ \\
\hline None & $3(7.0 \%)$ & $2(16.7 \%$ \\
\hline
\end{tabular}


receive enough support. This was not universal and was dependent on their individual situation as some felt highly supported, especially when completing it alongside another GPCPs. Whether the participants received supervision impacted the feasibility of its completion. Educational supervisors were felt to provide support in areas including training facilitation, evidence collection and general completion of the CCF. Challenges with educational supervision were reported. These included the educational supervisors and GPCPs not being in the same practice, and the educational supervisor not having first-hand experience of completing the framework:

\section{"...that there's not a massive amount of direction for [the educational supervisors] either, and because they haven't been through it, you know like the blind leading the blinder." (P12)}

Clinical supervisors, often GPs, were seen to have a more "hands-on" role and were reported to shadow clinics, provide peer review sessions and give feedback. Challenges were reported, with participants finding that the clinical supervisors had little knowledge or experience of the CCF and suggested that often GPs did not want to be supervisors:

“... the GPs, some of them are quite reluctant to be signed up as mentors... because they don't want to put in a huge amount of work." (P10)

The format and content of the hard copy of the CCF and TURAS influenced perceptions of feasibility. There were mixed views of the CCF's hard copy with some suggesting that they found it difficult to carry and that the amount of content was overwhelming. However, some participants conversely were supportive of the amount of content, as it meant they only had to refer to one place for guidance.

The online resource (TURAS) was reported as being incomplete as there was content in the CCF's hard copy that was missing in the online resource. There was also confusion over the formatting as some participants were unsure of where to upload certain evidence:

"Yeah there was some evidence you couldn't

find a place for very well..." (P14).

Participants highlighted positive aspects of TURAS, suggesting that the formatting meant submitting evidence was simple and the word limit meant there was guidelines to work within. However, some interview participants also suggested that they or their supervisor created additional resources to help complete the CCF.

\section{DISCUSSION}

The current study aimed to understand GPCPs' perceptions of a competency-based educational resource package, and its ability to support them in practice. To explore their perceptions, GPCPs were asked to complete a questionnaire and/or an interview, based on the outcomes of adoption, acceptability, appropriateness, and feasibility from Proctor's model. ${ }^{32}$ The results suggested a high rate of adoption as most participants used both the CCFs hard copy and the online portfolio TURAS. The acceptability was influenced by the GPCPs' view on the purpose of the CCF, and its perceived worth to themselves and other staff within the General Practice. Participants indicated that the appropriateness of the CCF was dependent on the opportunities they had within their current role and which health setting they worked in before becoming GPCPs. Perceptions on the feasibility of completing the CCF varied depending on individual situations with regards to participants' available time, the support they received, and their perceptions of the resources' format and content.

The results showed that the majority of participants had adopted both the hard copy of the CCF and the online portfolio TURAS. This indicates there was value in using both resources together, and therefore they should remain as one resource package. The high adoption rate may, however, also be due to the sample itself, with those who interact with the CCF resources more likely to take part in research related to the resources. A minority of participants had not adopted the resources, which the results suggest is due to GPCPs not considering them useful, or relevant to their role. Another explanation for GPCPs not adopting the educational resource package is that participants do not find them feasible to complete, as it was indicated that in some cases the resources were incomplete, overwhelming or difficult to follow. This lack of feasibility may lead GPCPs to not adopt the package or to create their own resources to help with the completion.

The findings suggested that participants saw the benefit and purpose of completing the CCF. This is in line with past literature, as competency-based educational resources are evidence based and have been shown to be beneficial in several healthcare settings, including pharmacy. ${ }^{16-19,21}$ It is therefore important that there is continued use of the resources as a tool to develop GPCPs in their new roles in General Practice. Furthermore, internationally there has been an increase in primary care pharmacists, with some adopting competency-based education. ${ }^{17,24-27}$ It may be that all countries introducing pharmacists into General Practice should utilise competency-based education to help integrate them fully into practice and increase their confidence. However, the benefit of the resource may not be fully realised until its completion is recognised with a qualification indicating an enhanced skill set.

GPCPs' job role opportunities and previous experience were suggested to influence the appropriateness of the CCF. This finding is reinforced by a systematic review which found that the relevance of competency-based frameworks is dependent on the pharmacist's work environment, experience, and competence. ${ }^{40}$ The results also suggest that most GPCPs undertook tasks across all three levels of the pharmacotherapy service; however, it is unclear how the tasks were undertaken (for example, patient facing or supervisory). It was also indicated that the job role opportunities given to individual GPCPs, including completing tasks such as physical examination, differed; this further suggests variation in the role, which may influence the suitability of the CCF. This variation is similar to previous research that found that the tasks completed by pharmacists within General Practice were not standardised between pharmacists and practices. ${ }^{4,27,41,42}$ Possible causes for this variation in how the role is completed could be related to the funding available, pressures on the current systems, and differing 
local/national agendas. ${ }^{3,12}$ This poses a challenge to the implementation of competency-based resources as, for example, some competencies may be dependent on undertaking certain duties. This highlights that educational resources depend on all individuals having equivalent opportunities within their roles or allowing for various routes to evidence a competency. Future work may examine how the tasks an individual completes influences the appropriateness of the competency-based resource.

The impact of support on feasibility was notable, with effective supervision viewed as important to the use of the CCF. As part of the resource package educational supervisors were introduced to provide GPCPs with support in completing the CCF and providing feedback on their competence and capability. The results showed that the supervisors did provide support in the completion of the CCF; however, there were challenges in terms of the location of these supervisors and their availability. This is in line with previous research which suggested problems with the accessibility of supervision in several healthcare professions. ${ }^{43}$ Results suggested that clinical supervisors provided guidance with regards to their activities within the practice, which was valued by the GPCPs. However, individual GPCPs' access to the supervision varied, especially from clinical supervisors who were often GPs. This reluctance to provide support has been seen in previous research. ${ }^{25,44}$ A possible explanation for this is that GPCPs were recommended to GPs to save time in practice; however, research indicates that pharmacists commencing employment within General Practice require time and support from GPs to help with their initial development. ${ }^{2,15}$ Research suggests that pharmacists who are supported and integrated sufficiently are most effective, resulting in GPs acknowledging their usefulness. ${ }^{45}$ It may be that the development of an induction plan, led by GPs, would support the feasibility of the CCF by encouraging active engagement and support. Additionally, providing evidence on the effectiveness of pharmacists within primary care by understanding their outcomes, may also increase GP buy-in and support. Therefore, it is essential that there is supervisory support when new roles and associated educational resources are implemented as long-term benefits may not be realised without it.

A strength of the current study was its multi-method approach, including a previously validated questionnaire, and in-depth interviews which aimed to gain a full understanding of GPCPs' perceptions. ${ }^{35}$ To inform these approaches, Proctor's framework was used, which has been applied successfully in various settings and resulted in methods that focused on topics that influence implementation. ${ }^{32,46} \mathrm{~A}$ limitation of the study was that the response rate from the questionnaire was lower than expected, which may hinder the generalisability of the findings; however, it was positive that all Scottish health regions have been represented suggesting the results may be reflective of the national Scottish context. A further potential limitation relates to the fact that the interview and questionnaire participants groups may not be mutually exclusive, and therefore the views of some participants may be over-represented. Another possible limitation is that those who interact with the CCF are more likely to engage with research relating to it resulting in response bias; however, some participants indicated that they did not use the resources. Lastly, it should be noted that participants may be taking part in other professional frameworks which may have impacted the results.

\section{CONCLUSIONS}

Overall, competency-based educational resources within primary care General Practice pharmacy is considered valuable, with GPCPs adopting the resources and understanding the benefits. However, for the implementation of competency-based education to be fully successful, there should be steps taken to increase understanding and buy-in from others within General Practice. Additionally, the resources' success may be underpinned by supportive infrastructure such as supervision and time set aside for its completion. The resources should also be made suitable for all, as there is variation in how roles and tasks are done. By considering the differing individual situations, successful implementation of competency-based education is possible.

\section{ACKNOWLEDGEMENTS}

The contribution provided by Anne Watson, Fiona Stewart, Rachel Bruce and Ailsa MacDonald from NHS Education for Scotland is acknowledged.

\section{CONFLICT OF INTEREST}

The Authors declare that they have no conflicts of interest to disclose.

\section{FUNDING}

This work was supported by NHS Education for Scotland.

\section{AUTHOR ROLES (CRediT)}

Conceptualization: NMW, TM, RN, MB.

Formal analysis: KP, NMW.

Funding acquisition: $\mathrm{RN}, \mathrm{MB}$.

Investigation: KP, NMW.

Methodology: KP, NMW, TM, RN.

Writing - original draft: KP, RN.

Writing - review \& editing: KP, NMW, TM, RN, MB.

\section{References}

1. Barnes E, Ashraf I, Din A. New roles for clinical pharmacists in general practice. Prescriber. 2017;28(4):26-29. https://doi.org/10.1002/psb.1558

2. Bradley $F$, Seston $E$, Mannall $C$, Cutts $C$. Evolution of the general practice pharmacist's role in England: a longitudinal study. Br J Gen Pract. 2018;68(675):e727-e734. https://doi.org/10.3399/bigp18x698849 
Preston K, Weir NM, Mueller T, Newham R, Bennie M. Implementation of pharmacist-led services in primary care: A mixedmethods exploration of pharmacists' perceptions of a national educational resource package. Pharmacy Practice 2021 JulSep;19(3):2440

https://doi.org/10.18549/PharmPract.2021.3.2440

3. Maskrey M, Johnson CF, Cormack J, Ryan M, Macdonald H. Releasing GP capacity with pharmacy prescribing support and New Ways of Working: a prospective observational cohort study. Br J Gen Pract. 2018;68(675):e735-e742. https://doi.org/10.3399/bjgp18x699137

4. Stewart D, Maclure $\mathrm{K}$, Newham R, et al. A cross-sectional survey of the pharmacy workforce in general practice in Scotland. Fam Pract. 2020;37(2):206-212. https://doi.org/10.1093/fampra/cmz052

5. Kjosavik SR. Ongoing recruitment crisis In Norwegian general practice. Scand J Prim Health Care. 2018;36(2):107-108. https://doi.org/10.1080/02813432.2018.1462294

6. Maclsaac P, Snowdon T, Thompson R, Crossland L, Veitch C. General practitioners leaving rural practice in Western Victoria. Aust J Rural Health. 2000;8(2):68-72. https://doi.org/10.1046/j.1440-1584.2000.00232.x

7. Marchand C, Peckham S. Addressing the crisis of GP recruitment and retention: a systematic review. Br J Gen Pract. 2017;67(657):e227-e237. https://doi.org/10.3399/bjgp17x689929

8. Gardiner M, Sexton R, Durbridge M, Garrard K. The role of psychological well-being in retaining rural general practitioners. Aust J Rural Health. 2005;13(3):149-155. https://doi.org/10.1111/i.1440-1854.2005.00677.x

9. Owen K, Hopkins T, Shortland T, Dale J. GP retention in the UK: a worsening crisis. Findings from a cross-sectional survey. BMJ Open. 2019;9(2):e026048. https://doi.org/10.1136/bmjopen-2018-026048

10. Snell $R$, Langran $T$, Donyai $P$. Patient views about polypharmacy medication review clinics run by clinical pharmacists in GP practices. Int J Clin Pharm. 2017;39(6):1162-1165. https://doi.org/10.1007/s11096-017-0538-z

11. Ryan K, Patel N, Lau WM, Abu-Elmagd H, Stretch G, Pinney H. Pharmacists in general practice: a qualitative interview case study of stakeholders' experiences in a West London GP federation. BMC Health Serv Res. 2018;18(1):234. https://doi.org/10.1186/s12913-018-3056-3

12. Hampson N, Ruane S. The value of pharmacists in general practice: perspectives of general practitioners-an exploratory interview study. Int J Clin Pharm. 2019;41(2):496-503. https://doi.org/10.1007/s11096-019-00795-6

13. Develin A. Pharmacists in general practice - ACT pilot program: my journey so far. J Pharm Pract Res. 2017;47(4):308312. https://doi.org/10.1002/jppr.1367

14. Anderson C, Zhan K, Boyd M, Mann C. The role of pharmacists in general practice: A realist review. Res Social Adm Pharm. 2019;15(4):338-345. https://doi.org/10.1016/j.sapharm.2018.06.001

15. The Scottish Government. The 2018 general medical services contract in Scotland 2018. Edinburgh: The Scottish Government; 2017.

16. Hendry C, Lauder W, Roxburgh M. The dissemination and uptake of competency frameworks. J Res Nurs. 2007;12(6):689-700. https://doi.org/10.1177\%2F1744987107079652

17. Benson H, Lucas C, Benrimoj SI, Williams KA. The development of a role description and competency map for pharmacists in an interprofessional care setting. Int J Clin Pharm. 2019;41(2):391-407. https://doi.org/10.1007/s11096019-00808-4

18. Koster A, Schalekamp T, Meijerman I. Implementation of Competency-Based Pharmacy Education (CBPE). Pharmacy (Basel). 2017;5(1):10. https://doi.org/10.3390/pharmacy5010010

19. von Treuer KM, Reynolds N. A Competency model of psychology practice: Articulating complex skills and practices. Front Educ. 2017;2(54). https://doi.org/10.3389/feduc.2017.00054

20. Mucalo I, Hadžiabdić MO, Govorčinović T, Šarić M, Bruno A, Bates I. The Development of the Croatian Competency Framework for Pharmacists. Am J Pharm Educ. 2016;80(8):134. https://doi.org/10.5688/ajpe808134

21. Udoh A, Bruno-Tomé A, Ernawati DK, Galbraith K, Bates I. The effectiveness and impact on performance of pharmacyrelated competency development frameworks: A systematic review and meta-analysis. Res Social Adm Pharm. 2021;17(10):1685-1696. https://doi.org/10.1016/..sapharm.2021.02.008

22. Sokhi J, Desborough J, Norris N, Wright DJ. Learning from community pharmacists' initial experiences of a workplacebased training program. Curr Pharm Teach Learn. 2020;12(8):932-939. https://doi.org/10.1016/i.cptl.2020.04.017

23. Lim A, Arora G, Mclnerney B, Vienet M, Stewart K, Galbraith K. Evaluation of a new educational workplace-based program for provisionally registered pharmacists in Australia. Curr Pharm Teach Learn. 2020;12(12):1410-1416. https://doi.org/10.1016/i.cptl.2020.07.008

24. Benson H, Lucas C, Williams KA. Establishing consensus for general practice pharmacist education: A Delphi study. Curr Pharm Teach Learn. 2020;12(1):8-13. https://doi.org/10.1016/j.cptl.2019.10.010

25. Karampatakis GD, Ryan K, Patel N, Stretch G. Capturing pharmacists' impact in general practice: an e-Delphi study to attempt to reach consensus amongst experts about what activities to record. BMC Fam Pract. 2019;20(1):126. https://doi.org/10.1186/s12875-019-1008-6

26. Hazen A, de Groot E, de Gier H, Damoiseaux R, Zwart D, Leendertse A. Design of a 15-month interprofessional workplace learning program to expand the added value of clinical pharmacists in primary care. Curr Pharm Teach Learn. 2018;10(5):618-626. https://doi.org/10.1016/i.cptl.2018.01.006

27. Jorgenson D, Dalton D, Farrell B, Tsuyuki RT, Dolovich L. Guidelines for pharmacists integrating into primary care teams. Can Pharm J (Ott). 2013;146(6):342-352. https://doi.org/10.1177/1715163513504528

28. Groen A, Lucas C, Benson H, Alsubaie M, Boyd MJ. A systematic review of postgraduate training programmes directed at pharmacists entering primary care. Pharm. Educ. 2020;20:313-323. https://doi.org/10.46542/pe.2020.201.313323

29. NHS Education for Scotland. General practice clinical pharmacist: Competency and capability framework. Edinburgh: NHS Education for Scotland; 2016.

30. Falender CA, Shafranske EP. Clinical supervision: the state of the art. J Clin Psychol. 2014;70(11):1030-1041. https://doi.org/10.1002/jclp.22124

31. Day E, Brown N. The role of the educational supervisor: A questionnaire survey. Psychiatr Bull R Coll Psychiatr. 2000;24(6):216-218. 
Preston K, Weir NM, Mueller T, Newham R, Bennie M. Implementation of pharmacist-led services in primary care: A mixedmethods exploration of pharmacists' perceptions of a national educational resource package. Pharmacy Practice 2021 JulSep;19(3):2440.

https://doi.org/10.18549/PharmPract.2021.3.2440

32. Proctor $\mathrm{E}$, Silmere $\mathrm{H}$, Raghavan $\mathrm{R}$, et al. Outcomes for implementation research: conceptual distinctions, measurement challenges, and research agenda. Adm Policy Ment Health. 2011;38(2):65-76. https://doi.org/10.1007/s10488-010-0319-7

33. Blanchard CM, Duboski V, Graham J, et al. A mixed methods evaluation of the implementation of pharmacy services within a team-based at-home care program [published online, 2021 Mar 2]. Res Social Adm Pharm. 2021;[ahead of print]. https://doi.org/10.1016/j.sapharm.2021.02.017

34. Schoonenboom J, Johnson RB. How to Construct a Mixed Methods Research Design. Kolner Z Soz Sozpsychol. 2017;69(Suppl 2):107-131. https://doi.org/10.1007/s11577-017-0454-1

35. Weiner BJ, Lewis CC, Stanick C, et al. Psychometric assessment of three newly developed implementation outcome measures. Implement Sci. 2017;12(1):108. https://doi.org/10.1186/s13012-017-0635-3

36. Santos JRA. Cronbach's alpha: A tool for assessing the reliability of scales. J Exten. 1999;37(2):1-5.

37. Elo S, Kyngäs H. The qualitative content analysis process. J Adv Nurs. 2008;62(1):107-115. https://doi.org/10.1111/j.1365-2648.2007.04569.x

38. Gale NK, Heath G, Cameron E, Rashid S, Redwood S. Using the framework method for the analysis of qualitative data in multi-disciplinary health research. BMC Med Res Methodol. 2013;13:117. https://doi.org/10.1186/1471-2288-13-117

39. Clarke V, Braun V. Thematic analysis. In: Encyclopaedia of critical psychology. New York, NY: Springer; 2014.

40. Udoh A, Bruno-Tomé A, Ernawati DK, Galbraith K, Bates I. The development, validity and applicability to practice of pharmacy-related competency frameworks: A systematic review. Res Social Adm Pharm. 2021;17(10):1697-1718. https://doi.org/10.1016/i.sapharm.2021.02.014

41. Butterworth J, Sansom A, Sims L, Healey M, Kingsland E, Campbell J. Pharmacists' perceptions of their emerging general practice roles in UK primary care: a qualitative interview study. Br J Gen Pract. 2017;67(662):e650-e658. https://doi.org/10.3399/bjgp17x691733

42. Nabhani-Gebara S, Fletcher S, Shamim A, et al. General practice pharmacists in England: Integration, mediation and professional dynamics. Res Social Adm Pharm. 2020;16(1):17-24. https://doi.org/10.1016/i.sapharm.2019.01.014

43. Kilminster SM, Jolly BC. Effective supervision in clinical practice settings: a literature review. Med Educ. 2000;34(10):827840. https://doi.org/10.1046/i.1365-2923.2000.00758.x

44. Buist E, McLelland R, Rushworth GF, et al. An evaluation of mental health clinical pharmacist independent prescribers within general practice in remote and rural Scotland. Int J Clin Pharm. 2019;41(5):1138-1142. https://doi.org/10.1007/s11096-019-00897-1

45. Blondal AB, Sporrong SK, Almarsdottir AB. Introducing Pharmaceutical Care to Primary Care in Iceland-An Action Research Study. Pharmacy (Basel). 2017;5(2):23. https://doi.org/10.3390/pharmacy5020023

46. Powell BJ, Proctor EK, Glass JE. A Systematic Review of Strategies for Implementing Empirically Supported Mental Health Interventions. Res Soc Work Pract. 2014;24(2):192-212. https://doi.org/10.1177/1049731513505778

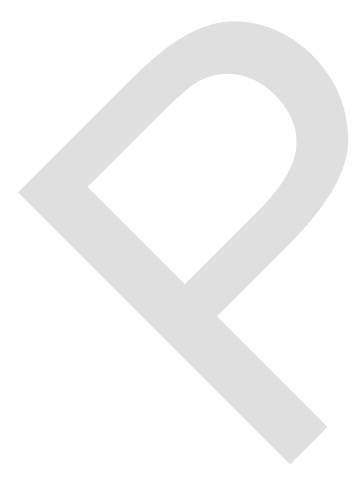

